\title{
Historias entrelazadas. El intercambio académico en el siglo XX: México, Estados Unidos, América Latina
}

Misael Armando Martínez Ranero

Universidad Nacional Autónoma de México, México

misael_ranero@hotmail.com

Sebastián Rivera Mir (coord.), Historias entrelazadas. El intercambio académico en el siglo XX: México, Estados Unidos, América Latina, Zinacantepec, Estado de México, El Colegio Mexiquense, A. C., 2020, 236 pp.

El siglo XX fue testigo de la disipación de las fronteras y del acortamiento de las distancias en términos mercantiles; sin embargo, ese fenómeno global no fue privativo del ámbito económico, sino que permeó en las distintas esferas de la sociedad. Historias entrelazadas centra su atención en el intercambio académico desde una perspectiva transnacional, aunque rescata con atino la especificidad local de las naciones que conforman el "sur global”, con México como país bisagra.

Precisamente la historia trasnacional puso en escena el estudio sobre las estancias de investigación, las becas de movilidad, la circulación del conocimiento y las múltiples modalidades del intercambio académico; empero, aún quedan muchos vacíos por llenar. La obra coordinada por Sebastián Rivera Mir cuenta con la aportación de nueve autores y constituye un excelente ejercicio de análisis y reflexión que atenúa dichos vacíos. A lo largo de sus páginas el lector transitará por territorio americano, desde los Estados Unidos hasta la parte más meridional del continente, para ir develando los flujos migratorios que voluntaria e involuntariamente devinieron en la construcción, consolidación y difusión del saber.

A su vez, la diversidad regional está acompasada por la variedad de los perfiles académicos abordados en los nueve capítulos que conforman el libro. Contrario a lo que podría suponerse, la multiplicidad territorial y disciplinaria de los sujetos de

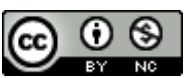

4.0 Internacional

Secuencia. Reseñas, 2021

http://secuencia.mora.edu.mx
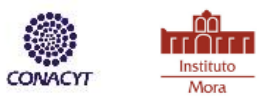
estudio no actúa como elemento de desarticulación; de hecho, la selección y el acomodo de cada uno de los textos propicia una lectura fluida y amena que, sin evadir el rigor metodológico, invita a explorar las latitudes y las áreas del conocimiento que escaparon de sus posibilidades o de sus intereses.

En términos temporales los escritos se inscriben dentro del convulso siglo XX, marcado por las dos Grandes Guerras y por el llamado contexto de Guerra Fría. Si bien esta acotación no niega la existencia de procesos similares en épocas anteriores, lo cierto es que cruzar las fronteras en aras del saber fue una alternativa que cobró relevancia bajo el amparo de las ciencias modernas y el despuntar tecnológico del siglo pasado. De tal suerte que, sin un afán totalizador, la obra aquí reseñada funciona como un termómetro que mide la circulación del conocimiento a través del tiempo según las condiciones propias de cada país, pero en negociación y diálogo con otras naciones y con la aceptación o el rechazo de los individuos.

En efecto, las trayectorias individuales son piezas fundamentales para comprender y explicar los intercambios académicos, es por ello por lo que los autores atienden las experiencias subjetivas como parte de una práctica formativa derivada de las aspiraciones y de las decisiones personales, sin desestimar el papel de los distintos gobiernos en el proceso. En ese sentido, Historias entrelazadas va más allá de lo académico; en lo individual, algunos flujos migratorios fueron resultado de los conflictos sociopolíticos que se suscitaron en Latinoamérica a lo largo del siglo XX; en lo colectivo, el fomento de los intercambios fue parte de una política educativa que además debía ajustarse a la línea económica, debía tener un impacto cultural y debía animar las relaciones diplomáticas entre los países involucrados.

Si se observa, la vida académica no puede reducirse a la selección de una carrera ni a la elección de alguna institución para estudiar o desarrollarse profesionalmente, puesto que, detrás de todas esas decisiones, existieron una serie de factores que iban desde lo más específico hasta lo más general y que, en menor o mayor medida, condicionaron el rumbo de los distintos actores. De tal modo, mientras que el eje teórico está perfectamente definido por la historia transnacional, el abordaje permite múltiples adscripciones historiográficas que conjuntan lo novedoso con lo integral. 
A todos los rasgos de diversidad que se han ido enunciando debe agregarse otro no menos importante: la formación y el origen de los colaboradores. Los lugares de enunciación y de producción enriquecen los textos con la pluralidad de enfoques $\mathrm{y}$ fuentes que van desde entrevistas $\mathrm{y}$ archivos personales, hasta archivos institucionales y nacionales. Para efectos de sistematización el volumen fue dividido en dos secciones: I. Lo transnacional y sus flujos y II. Política e intercambio. División que, a mi entender, resulta innecesaria porque los capítulos bien podrían ser intercambiables sin desarmonizar al resto; no obstante, lejos de verlo como error, es una cualidad que remarca el nivel de coordinación y las horas de discusión tras bambalinas, en este caso, previo a la publicación.

En el primer capítulo, Adriana Minor García aborda las dinámicas de movilización del conocimiento a partir de la figura del "actor transnacional"; es decir, personajes que trascienden fronteras mediante vínculos personales y profesionales. Para tejer su argumento, la autora analiza la trayectoria de tres físicos destacados, cuyas experiencias individuales y colectivas, detonadas por la migración en un contexto estimulador - que posibilita y restringe-, generaron identidades híbridas $\mathrm{y}$ al mismo tiempo crearon conexiones que movilizaron personas e ideas $\mathrm{y}$ produjeron conocimiento. Así, las rutas que siguieron esos científicos pueden ser examinadas como parte de flujos migratorios de mayor envergadura, razonamiento que bien puede funcionar como punto de partida para investigaciones ulteriores y que constituye una de las aportaciones de Minor García.

Rachel Grace Newman lleva la discusión hacia un plano más conceptual en el segundo capítulo, en un contexto en el que estudiar en el extranjero se convirtió en un elemento de diferenciación social, se hizo necesario definir si el intercambio académico es migración o mera movilidad. De manera elocuente, la autora nos convence de que la movilidad estudiantil más allá de los límites nacionales es por definición parte del fenómeno migratorio, asociación que, por lógica que pueda parecer, ha sido desatendida por los estudios históricos del tema.

En concordancia con una de las líneas generales del libro, Newman ilustra cómo el intercambio académico y su análisis no se reduce a lo estrictamente 
académico, puesto que el proceso implica la adaptación a una nueva forma de vida y los factores que intervienen en la toma de decisión son variados; así como algunos se dirigieron a las universidades estadunidenses en busca de preparación y prestigio académico, otros, ante el vacío institucional y la limitada oferta educativa en sus respectivos países, optaron por salir en busca de mejores oportunidades.

Sobre esto último nos habla Marco Vinicio Calderón Blanco en el tercer capítulo, haciendo explícita una segmentación que aparece en otras colaboraciones y que bien podría aplicar para el resto, la cual consiste en analizar el flujo educativo entre Costa Rica y México en función de tres momentos: antes (creación y difusión de los programas de becas), durante (experiencias de la estadía) y después (retorno al lugar de origen) de la estancia. Si bien cada fase puede ser tan relevante como las otras, el texto permite inferir que el tercer momento era medular para reanimar el ciclo, toda vez que la culminación de los cursos, pese a las vicisitudes, generaba una imagen positiva de los gobiernos e instituciones que promovieron las becas $\mathrm{y}$ repercutía favorablemente en aquellos que, a su regreso, ocuparon los cargos de reciente creación e inspiraron a las futuras generaciones de profesionistas.

En el capítulo cuatro, Joel Vargas-Domínguez propone investigar las redes que posibilitan la construcción y la movilización del conocimiento y su interacción entre el plano local y global. La incorporación y el uso de los conocimientos científicos conlleva un proceso de adaptación y resistencia local que pone en entredicho, o al menos cuestiona, su pregonada universalidad. Las lecturas tradicionales invitan a pensar en un flujo del conocimiento norte-sur, con una marcada hegemonía norteamericana; no obstante, Vargas-Domínguez sugiere que en el caso de la nutrición - estudiado a partir de la trayectoria profesional del mexicano José Quintín Olascoaga-, las particularidades de los problemas locales propiciaron una mayor incidencia entre los países latinoamericanos.

Por su parte, en el capítulo cinco, Diana Alejandra Méndez Rojas examina la labor filantrópica y científica de la Fundación Rockefeller en el marco de la "revolución verde" en América Latina, como parte de un proyecto transnacional que debió adaptarse a los ritmos y circunstancias nacionales. El caso de Alfredo Carballo Quirós sirve para abordar el fenómeno desde la especificidad costarricense; para 
Carballo, la especialización académica era fundamental para el progreso de la agronomía y para combatir el empirismo que privaba en Costa Rica. Curiosamente, sugiere Méndez Rojas, las condiciones de su país no alentaban tal especialización, puesto que no contaban con lo necesario para ponerla en práctica; de tal suerte que, el primer paso obligado estuvo en manos de los técnicos, quienes contaban con los conocimientos adecuados para la realidad centroamericana que contrastaba con las pautas idealizadas que se dictaban desde las instituciones estadunidenses.

La segunda sección inicia con la colaboración de David Antonio Pulido García, quien, mediante el uso de la categoría de "jóvenes intelectuales", analiza el papel político-intelectual de dicho sector en los movimientos estudiantiles acaecidos al término de la Primera Gran Guerra en este lado del Atlántico. En los albores del siglo $\mathrm{XX}$, las organizaciones estudiantiles en Colombia estaban en ciernes, Carlos Pellicer arribó a Bogotá en diciembre de 1918 con un panorama poco alentador que se transformó en reto y que Pulido García relata con agudeza. A diferencia de los protagonistas de los capítulos subsecuentes, la movilidad de Pellicer no fue ocasionada por algún conflicto sociopolítico, situación que remite a lo innecesario de la división que descarta o descubre similitudes a conveniencia y que incita a pensar que la política y lo transnacional están disociados. ${ }^{1}$

En el séptimo capítulo, Sebastián Rivera Mir se centra en el itinerario de Aníbal Ponce en México y en el impacto de su obra. Los conflictos políticos de Argentina trajeron a Ponce a costas mexicanas en febrero de 1937, territorio donde fungió como académico sin renunciar a su activismo. El posicionamiento ideológico del argentino, contrario a lo que ocurrió en su patria, se vio acompasado por la educación socialista impulsada durante el sexenio cardenista, aunque Rivera Mir advierte que no debe entenderse como una plena concordancia entre el intelectual y su círculo, sino más bien, como un vínculo dinámico del que ambas partes se beneficiaron y al que ambos retribuyeron.

\footnotetext{
${ }^{1}$ Sin un afán reduccionista, lo transnacional y sus flujos encaja perfectamente dentro de las políticas globales, de las políticas de Estado, de las políticas educativas, de las políticas económicas y de otras tantas políticas que justifican y dan sentido a los intercambios académicos.
} 
Carlos Escalante Fernández propone la categoría de "intercambio académico no ortodoxo" para abordar la intermitente, pero significativa estadía de Paulo Freire en México. Dividido en tres partes, el capítulo ocho nos presenta la vida del agente (Freire) y nos introduce en la estructura (el Centro Intercultural de Documentación) para finalmente exponer los efectos de la confluencia que, entre otras cosas, le permitió al brasileño difundir sus ideas en nuestro país. La convivencia y los diálogos que Freire entabló con austriacos, británicos, alemanes, peruanos y brasileños en Cuernavaca fueron cruciales para la consolidación intelectual que devino en las obras de aquellos grandes pensadores.

Finalmente, en el capítulo nueve, Malena Beatriz Alfonso se interesa por la experiencia exiliar de Néstor Braunstein y su participación en la producción del conocimiento disciplinar. Su "refugio" en México sirvió como punto de inflexión en su estatus profesional como psiquiatra y psicoanalista; mientras que, con la publicación de su obra Psicología: ideología y ciencia en 1975, Braunstein cimbró "la enseñanza académica de la psicología en toda Latinoamérica" (p. 222). Este último capítulo condensa los ejes analíticos de la obra, a saber: parte de una figura central para exponer el contexto de salida, el contexto de llegada, el contexto de permanencia y el contexto de trascendencia. Denominaciones artificiales que se articulan en función del intercambio académico y que, analizadas a profundidad, dan cuenta de la producción y socialización del conocimiento a escala local e internacional.

Después de todo, los desequilibrios y las asimetrías formativas que advierte Rivera Mir en la introducción del volumen se mantienen vigentes y el anhelo por acceder a las instituciones educativas de mayor prestigio, ya sea como académicos o estudiantes, continúa siendo una alternativa para conformar un proyecto de vida y, por añadidura, parte de un fenómeno que vale la pena historiar. Así, este libro se convierte en el pretexto ideal para adentrarse en los intercambios académicos, con todas las implicaciones ya enunciadas, y bien puede servir de guía e inspiración para todos aquellos que deseen entrelazar historias. 